\title{
TRAUMA-INFORMED CARE: AN ECOLOGICAL RESPONSE
}

\author{
Carmela J. DeCandia, Psy. D. \\ Center for Social Innovation

\section{Kathleen Guarino} \\ American Institutes for Research
}

Exposure to traumatic stress is increasingly understood as a common denominator of children and youth across service systems. Unlike the usual stresses of our daily lives, traumatic experiences occur outside the realm of usual experience, threaten one's life or bodily integrity, and invoke intense feelings of helplessness, powerlessness, and terror (American Psychological Association, 2008). These events "overwhelm the ordinary systems of care that give people a sense of control, connection, and meaning" (Herman, 1992).

Exposure to traumatic experience is common for children and adolescents across service systems. For example, in community samples, more than two-thirds of children report experiencing a traumatic event by age 16 (Copeland, Keeler, Angold, \& Costello, 2007). One in four children attending school have been exposed to a traumatic event (National Child Traumatic Stress Network Schools Committee, 2008), and over $80 \%$ of children and youth who live in dangerous neighborhoods have experienced trauma (National Center for Children in Poverty, 2007). Interpersonal violence is one of the most common forms of traumatic stress for children and youth. Based on the National Survey of Children's Exposure to Violence (NatSCEV), 38\% of children and youth ages 2-17 reported more than one type of direct victimization in the previous year, and nearly half (49\%) suffered two or more types of direct or indirect victimization (Finkelhor, Turner, Ormrod, Hamby, \& Kracke, 2009).

Advances in the neurological and developmental sciences have brought an explosion of evidence demonstrating the devastating, long-term impact of traumatic stress on the developing brain and body (Center on the Developing Child at Harvard University, 2010; Felitti et al., 1998; Felitti \& Anda, 2010; Shonkoff et al., 2012a, 2012b; Shonkoff \& Phillips, 2000; van der Kolk, Roth, Pelcovitz, Sunday, \& Spinazzola, 2005). As severe stresses and traumatic events accumulate, the physiological and psychological impact becomes more profound, resulting in a range of adverse responses including neurobiological changes, difficulties regulating affect, and problems forming supportive relationships (Cook et al, 2005; National Scientific Council on the Developing Child, 2005; van der Kolk et al., 2005). As a result, many survivors of trauma suffer the debilitating consequences for the remainder of their lives.

Historically, health and human service systems have served people who have experienced trauma without understanding its impact and the need for tailored 
responses (Harris \& Fallot, 2001). However, as the science of traumatic stress has evolved, it can no longer be ignored in public systems of care. This recognition has galvanized a cross-sector call to action, from the local to federal levels, to adopt trauma-informed care as a practice across service settings (Report of the Federal Partners Committee on Women and Trauma, 2011).

Trauma-informed care represents an emerging shift in paradigm and practice. An ecological approach, trauma-informed care can be viewed as a universal design for serving trauma survivors; the entire system is used as a vehicle for intervention (Bloom, 1997; Clervil \& DeCandia, 2013; Guarino et al., 2009; Guarino, 2014; Harris \& Fallot, 2001; Hopper, Bassuk, \& Olivet, 2010; Substance Abuse and Mental Health Services Administration (SAMHSA), 2014). Trauma-informed care is a "strengths-based framework that is grounded in an understanding of and responsiveness to the impact of trauma that emphasizes physical, psychological, and emotional safety for both providers and survivors; and creates opportunities for survivors to rebuild a sense of control and empowerment" (Hopper, Bassuk, \& Olivet, 2010, p. 82). Accomplishing this requires a commitment and a coordinated effort at all levels - federal, state, and local-to changing the practices, policies, and cultures of entire organizations within and across systems, using knowledge of trauma and recovery to design and deliver services (Guarino et al., 2009; Guarino, 2012).

This article provides a comprehensive review of trauma-informed care-its evolution, current models and practice, and evidence base. First, we discuss the contextual factors underlying this paradigm shift. Next, we review the current state of the field, and lastly, we conclude with a discussion of research, policy, and practice implications. We pose the following questions: Is the field ready to embrace this paradigm and respond with a new perspective and practice? How can the pitfalls of the past be avoided? What will it take to build and sustain a truly trauma-informed system of care?

\section{The Evolution of Trauma-Informed Care}

As a society, we have a long history of alternately denying and prioritizing traumatic stress as a cause of suffering (Bloom, 2000; Herman, 1992; McFarlane, 2000; Ringel, 2012). When denied, the paradigm of individual responsibility and individual pathology leading to a "blame the victim" mentality prevails; when prioritized, social context and the impact of environment, experience, and relationships on human development are seen as central to the cause of, and solution to, human suffering. In her book, Trauma and Recovery, Herman (1992) writes, "The study of psychological trauma has a curious history ... Periods of active investigation have alternated with periods of oblivion. Repeatedly, in the past century, similar lines of inquiry have been taken up and abruptly abandoned, only to be rediscovered much later ... It [the field] has been periodically forgotten and must be periodically reclaimed" (p. 7). 
Why does this occur? To study or treat those affected by traumatic stress demands engaging with the reality and magnitude of violence and abuse in our society. Often the feelings associated with this reality are too much to bear (Ringel, 2012). "The larger society will continue to deny the magnitude of the problem, not only because of the emotional arousal exposure causes, but also because it is becoming increasingly clear that fixing the problems and actually preventing trauma will cost a great deal" (Bloom, 2000, p. 45). Denial allows us to distance ourselves from the feelings and moral obligations to act; the consequence is that pathology and intervention are situated within the individual rather than the social realm (Bloom, 2000; Herman, 1992; McFarlane, 2000).

Shifts in society's consciousness about trauma often occur following periods of war (Herman, 1992; McFarlane, 2000; Ringel, 2012; Terr, 1990) and when supported by social, humanitarian, and political movements (Bloom, 2000). For example, the acceptance of posttraumatic stress disorder (PTSD) in the Diagnostic and Statistical Manual-III in 1980 was preceded by almost two decades of cultural and political movements focused on civil rights, as well as the ending of the Vietnam era that for the first time graphically televised the trauma of war to the American public. This period supported the reemergence of the study of traumatic stress among veterans and linked it to the trauma of rape survivors and child abuse (Benedek \& Ursano, 2009; Bloom, 2000; Figley, 2002; Kramer \& Greene, 1997; McFarlane, 2001; SAMHSA, 2014).

The current sociopolitical climate, including post-9/11 and military actions Operation Iraqi Freedom and Operation Enduring Freedom, combined with the mounting neurodevelopmental research on the prevalence and impact of trauma, and the recognition of the social determinants of health (e.g., family and community factors), have created a context ripe for further evolution of the trauma field. Traumatic stress is once again being viewed as central to the problems of those served by our health and human service systems, and ecological responses that can be brought to scale are gaining favor. This context has begun to unite policymakers, researchers, and service providers, setting the stage for the current paradigm shift to trauma-informed care (Report of the Federal Partners Committee on Women and Trauma, 2011; SAMHSA, 2014).

\section{Awareness of Violence and Trauma in the Lives of Children, Youth, and Families}

Over the past two decades, researchers have documented the prevalence of trauma in the lives of children and youth across service sectors; the staggering numbers are impossible to ignore. For the nearly 500,000 children in the foster care system (U.S. Department of Health and Human Services, 2012), traumatic experiences include abuse, neglect, and significant family stressors (Stukes Chipungu \& Bent-Goodley, 2004). In the juvenile justice system, up to $90 \%$ of youth reported having experienced at least one traumatic event (Ford, Hartman, Hawke, 
\& Chapman, 2008). Of psychiatrically hospitalized adolescents, $93 \%$ have histories of physical or sexual and emotional trauma (Lipschitz et al., 1999). In addition, children in the homeless service system demonstrate high rates of lifetime trauma (Anooshian, 2005; Gewirtz, 2010). By age 12, 83\% have been exposed to at least one serious violent event (Bassuk et al., 1996; Bassuk et al., 1997; Buckner, Beardslee, \& Bassuk, 2004).

The rates of trauma for children's parents across service sectors are also extraordinarily high. For example, in the public mental health sector, $51-98 \%$ of adult clients with severe mental illness have experienced childhood physical or sexual abuse (Cusack, Frueh, Heirs, Suffoletta-Maierie, \& Bennett, 2003; Goodman et al., 1999; Mueser et al., 1998). In substance abuse settings, 75\% of clients report histories of significant trauma (Jennings, 2004).

Exposure to interpersonal violence is considered a major cause of post-trauma responses for women (Report of the Federal Partners Committee on Women and Trauma, 2011). It is so widespread that many consider it a normative experience. In a nationally representative survey, nearly 1 in 5 women reported experiencing rape at some time in their lives, and more than 1 in 3 women have experienced rape, physical violence, or stalking by an intimate partner (CDC, 2012a; CDC, 2010). In mental health settings, over 50\% of women report experiences of domestic violence (Friedman \& Loue, 2007; Mowbray, Oyserman, Saunders, \& Rueda-Riedle, 1998). In the criminal justice sector, $96 \%$ of female offenders have experienced trauma (Sarchiapone, Carli, Cuomo, Marchetti, \& Roy, 2009), most often related to sexual abuse and domestic violence (Battle, Zlotnick, Najavits, Gutierrez, \& Winsor, 2002; Zlotnick, Najavits, Rohsenow, \& Johnson, 2003).

Low-income populations are disproportionately affected by trauma and served by social service systems of care. Unemployment and severe poverty, conditions that unduly affect African American and Latino populations, leave many low-income adults feeling frustrated, ashamed, and hopeless, and at increased risk for relationship violence (Catlett, Toews, \& Wahilko, 2010; Daly, Power, \& Gondolf, 2001; Heise \& Garcia-Moreno, 2002; Kantor \& Jasinski, 1998). For example, research indicates that over $90 \%$ of severely poor, homeless mothers have a lifetime history of trauma (Bassuk et al., 1996, 1997; Hayes, Zonneville, \& Bassuk, 2013), $81 \%$ experienced multiple traumas, and more than half were victimized as children (Hayes, Zonneville, \& Bassuk, 2013). Similarly, low-income minority men experience high rates of violence in their lives, few social supports, and high rates of PTSD (National Center for Injury Prevention and Control, 2003; Rich \& Grey, 2005). The consequences of untreated trauma for mothers and fathers can be profound for the next generation. 


\section{Neurodevelopmental and Economic Impact of Trauma}

A growing body of research has emerged on the impact of traumatic stress. Advancing knowledge of the neurobiology of trauma offers compelling evidence of its long-term impact on the brain and body, and the significant costs to society when trauma goes unaddressed.

An event becomes traumatic when it overwhelms the neurophysiological system for coping with stress and leaves people feeling unsafe, vulnerable, and out of control (Herman, 1992; Macy, Behar, Paulson, Delman, \& Schmid, 2004). In the face of a confirmed threat, the amygdala and hypothalamus, structures in the limbic system - the brain's emotional control center-activate the body's survival responses: fight (actively confronting the source of the stress), flight (avoiding the stress), or freeze (shutting down) (Cohen et al., 2002; Perry, 2001; Saxe et al., 2006). Neurohormones, including adrenaline and cortisol, prepare the body for action to combat the threat and protect itself, and later, support a return to a physiological state of balance once the threat has passed (Perry \& Pollard, 1998; Perry et al., 1996). Real and perceived threats continually retrigger the stress response, causing a person's neurological system to go into a state of disequilibrium. In this constantly dysregulated state, an array of maladaptive behavioral responses can develop.

For children, exposure to early and ongoing traumatic stress (e.g., child abuse, neglect, family violence) without adequate parental and other supports can lead to a "toxic stress" response that has profound effects on brain development (Center for the Developing Child at Harvard University, 2010; Cook et al., 2005). The neurobiological impact of prolonged heightened stress responses and elevated stress hormones includes changes to brain architecture and to the functioning of neural pathways including those associated with learning, memory, and the ability to self-regulate and cope. Also, it results in a heightened baseline state of physiological arousal and increased sensitivity to internal and external triggers (Cohen et al., 2002; National Scientific Council on the Developing Child, 2005; Perry, 2001; Perry et al., 1996; Putnam, 2006; Saxe et al., 2006). These alterations place children at greater risk for adverse developmental, emotional, functional, and academic outcomes (Berliner, 2006; Cook et al., 2005; Fairbank \& Fairbank, 2009; Hopson \& Lee, 2011; van der Kolk et al., 2005).

Trauma that goes unrecognized and unaddressed in childhood has longterm individual and societal implications. The groundbreaking Adverse Childhood Experiences (ACE) Study highlights the significant connection between childhood exposure to trauma and adverse adult outcomes. Specifically, multiple ACE (e.g., physical or sexual abuse, witnessing violence) are associated with social, emotional, and cognitive impairment; high-risk behaviors as coping mechanisms (e.g., eating disorders, smoking, substance use, self-harm); severe health problems; and greater risk of early death (Felitti \& Anda, 2010; Felitti et al., 1998). 
The cost of not addressing trauma in both human and economic terms is significant. PTSD, often a chronic condition lasting for many years, is comparable to that of other serious mental disorders (Kessler, 2000). For example, for female victims of domestic violence, $50 \%$ suffer from clinical depression and $24 \%$ meet criteria for PTSD (Goodwin, Chandler, \& Meisel, 2003). Children who witness domestic violence also suffer from high rates of PTSD, depression, and anxiety and are at greater risk for becoming perpetrators of violence as adults (Ehrensaft et al., 2003; Kitzmann, Gaylord, Holt, \& Kenny, 2003; Renner \& Slack, 2006; Wolfe et al., 2003).

It is estimated that for domestic violence alone, the total cost across health, justice, and child serving systems is $\$ 37$ billion annually (National Center for Injury Prevention and Control, 2007). In addition, the lifetime cost for child maltreatment per victim is approximately $\$ 210,000$ in 2010 dollars (Fang, Brown, Florence, \& Mercy, 2012). Just one year of confirmed cases of child maltreatment is estimated to cost approximately $\$ 124$ billion (Fang et al., 2012; CDC, 2012b). Costs impact healthcare, employment, child welfare, criminal justice, and education. Taken together, the extraordinary toll that traumatic stress and interpersonal violence can take on individuals and society necessitates that we address trauma, and its impact, across all systems of care.

\section{An Ecological View of Trauma and Intervention}

Awareness of trauma and advances in the science of traumatic stress have helped practitioners in the field to understand, diagnose, and address posttrauma responses. PTSD is now a well-established diagnostic category (American Psychiatric Association, 2013); as a diagnosis, it is unique in its focus on context in the cause and relief of symptom expression (United States Department of Veterans Affairs, 2014).

Within the field, there is growing interest in understanding more about the complex manifestations of PTSD and its relationship to individual and external factors, (e.g., age of onset, number and type of traumatic experiences, social supports, and family and cultural context) (Cook et al., 2005). In particular, much attention has recently been paid to understanding the dynamic relationship between risk and protective factors. Research on trauma and resiliency highlights the importance of factors beyond individual traits in the human response to traumatic experiences (Bonanno et al., 1995, 2002, 2004; Bonanno, 2014; Cutuli \& Herbers, 2014; Harvey, 2007; Masten et al., 1999, 2011; Masten \& Coatsworth, 1995, 1998; Masten, Herbers, Cutuli, \& Lafavor, 2008; Pat-Horenczyk, Rabinowitz, Rice, \& Tucker-Levin, 2009). This represents a move away from a strictly medical model of individual illness towards a broader understanding of how environmental factors impact functioning and recovery (Bloom, 1997; Harvey, 2007; SAMHSA, 2014).

Trauma-informed care represents an ecological approach to trauma intervention based on the understanding that (a) environmental factors influence well- 
being; (b) health is, at least in part, socially-determined; and (c) interventions must target individual, interpersonal, and community systems (Bronfenbrenner \& Morris, 1998; SAMHSA, 2014; Saxe et al., 2006). This approach reflects a heightened awareness of context and the role that providers play in hindering or fostering recovery for trauma survivors (Harris \& Fallot, 2001; Jennings, 2008). From an ecological perspective, organizations and systems are seen as critical targets of trauma intervention. As such, the focus of interventions expands beyond the individual therapy hour into the larger environment. As the paradigm shifts from asking survivors "what's wrong with you," to "what happened to you" (Harris \& Fallot, 2001; SAMHSA, 2014), trauma-informed care broadens the approach to intervention from "how can I fix you" to "what do you need to support your development and recovery?"

\section{Trauma-Informed Care: Current Models and Practice}

As an outgrowth of the study of traumatic stress, trauma-informed care is relatively new. The U.S. Department of Health and Human Services Substance Abuse and Mental Health Services Administration (SAMHSA) spearheaded this movement and led the call for trauma-informed care. The seminal Women CoOccurring Disorders and Violence Study, a five-year multisite study that began in 1998, was the first federal effort to address the service needs of women with co-occurring substance use and mental health disorders who experienced trauma and helped set the federal direction around trauma-informed care (Moses, Reed, Mazelis, \& D'Ambrosio, 2003). SAMHSA continues to be a leader in the field in defining and integrating trauma-informed care with efforts including supporting the National Child Traumatic Stress Network (NCTSN) to develop and pilot interventions to address the mental health impact of traumatic stress on children; launching its National Center for Trauma-Informed Care (NCTIC) to provide training and consultation to support service systems, particularly behavioral health, to address trauma; and most recently, developing a comprehensive treatment improvement protocol (TIP) to set the standard for trauma-informed care in behavioral health (SAMHSA, 2014).

In addition to federal leadership, many others played an early role in shaping the field of trauma-informed care. The National Association of State Mental Health Program Directors (NASHMPD), who passed a resolution in 1999 to recognize the pervasive impact of violence and trauma, called for trauma-specific services in mental health agencies, and developed criteria for building a traumainformed mental health system (Power, 2011). In 2001, Maxine Harris and Roger Fallot published Using Trauma Theory to Design Service Systems, and articulated an early vision of trauma-informed care in social service systems. In addition, Sandra Bloom's Sanctuary model brought trauma-informed care to the therapeutic milieu within residential treatment and beyond (Bloom, 1997). 


\section{Current Models and Tools for Implementing Trauma-Informed Care}

A range of established models and tools have been developed to help organizations become trauma-informed. In Using Trauma Theory to Design Service Systems, Harris and Fallot (2001) articulate a comprehensive array of strategies that organizations can take to adopt trauma-informed care. To accompany this book, Community Connections developed Creating Cultures of Trauma-Informed Care (CCIT), a model that includes (a) a trauma-informed services self-assessment and planning protocol; (b) a trauma-informed self-assessment checklist; and (c) a trauma-informed services implementation form (Fallot \& Harris, 2011). Sandra Bloom's Sanctuary model offers organizations concrete tools for operationalizing the model's core principles within milieu settings (Bloom, 1997). The Sanctuary Institute offers intensive training and consultation over several years to fully adopt the model.

In addition to these models, there are a number of organizational self-assessments to guide agencies through the change process including Maine's System of Care Trauma-Informed Agency Assessment for child serving agencies (Yoe, Hornby, Goan, \& Tiernan, 2012); The National Council for Behavioral Health's Organizational Self-Assessment (National Council for Behavioral Health, unpublished); the Chadwick Center's Trauma System Readiness Tool for child welfare agencies (Chadwick Center for Children \& Families, 2013); and The National Center on Family Homelessness's Trauma-Informed Organizational Self-Assessment, adapted for homeless service settings, such as agencies that serve women veterans and community-based organizations that serve displaced children and families (Clervil, Guarino, DeCandia, \& Beach, 2013; Guarino et al., 2009; Guarino, 2011). Assessment tools include concrete benchmarks of trauma-informed care for daily practice. Though not formal measures of the extent to which an organization is trauma-informed, these tools provide a valuable roadmap and process for organization-wide, trauma-informed change.

\section{Key Components of Trauma-Informed Care}

Providing trauma-informed care requires an organizational commitment to building employees' awareness, knowledge, and skills to support recovery. At minimum, trauma-informed organizations endeavor to do no further harm and avoid retraumatizing clients (Moses, Reed, Mazelis, \& D'Ambrosio, 2003). Core principles of trauma-informed care across models include trauma knowledge, safety, choice, empowerment, and cultural competence (Hopper et al., 2010). Regardless of the services an agency provides, organizations can adopt these trauma-informed principles to assist those they serve in reaching goals and achieving success.

Providing trauma-informed care requires an organization-wide commitment to translating principles into concrete practices across all areas of programming. Although variability exists across current models, organizational domains identified as areas to target for developing trauma-informed practices include (a) sup- 
porting staff development; (b) creating a safe and supportive environment; (c) assessing and planning services; (d) involving consumers; and (e) adapting policies (Guarino et al., 2009).

\section{Implementation: Challenges of Shifting Models}

In traditional service systems, the impact of trauma is not well understood by providers, and traumatic experiences are generally not seen as related to problems or symptoms. Service providers are viewed as experts, and compliance by the client is expected. Force and coercion may sometimes occur to ensure compliance (Prescott, Soares, Konnath, \& Bassuk, 2008; Jennings, 2008; Bloom, 2000). Traditional systems may also cause additional harm by engaging in retraumatizing practices that mimic past trauma (e.g., rigid rules, lack of confidentiality, and harsh and punitive discipline practices) (Jennings, 2004, 2008). These experiences often leave trauma survivors feeling abused by the system and reluctant to trust service providers (Bloom, 2000; Elliott et al., 2005; Harris \& Fallot, 2001; Jennings, 2008).

Without an awareness of trauma and its impact, service providers run the risk of misunderstanding, misdiagnosing, and mistreating children and youth. Traumatized children and youth may seem emotionally out of control, avoid taking responsibility, and appear disruptive or withdrawn (Hodas, 2006). Providers may label these children as "oppositional" or "spacey" (Guarino \& Bassuk, 2010), or misdiagnose them as having ADHD, bipolar, or oppositional-defiant disorders (Cook et al., 2005; D'Andrea et al., 2012). Viewed on the basis of presenting symptoms alone, providers are likely to overlook the underlying traumatic experiences that may be the source of dysfunction (Cook et al., 2005; D'Andrea et al., 2012).

With training in trauma-informed care, providers and organizations can shift their perspectives and practices from the traditional to trauma-informed. For example, children's responses once viewed as disruptive are now understood as survival skills developed in response to earlier traumatic experiences. Changes in policies and practices may include (a) providing regular staff training on trauma and its impact; (b) reducing potentially triggering or retraumatizing practices such as restraint; (c) creating physical and emotional safety in relationships and in the environment; (d) using questions about trauma in all assessment protocol; and (e) giving survivors a voice and choice in all aspects of treatment (Guarino et al., 2009; Hopper et. al., 2010; SAMHSA, 2014). Finally, a trauma-informed approach takes into account the impact that working with trauma survivors has on providers (e.g., secondary traumatic stress) and includes practices to create a culture that supports provider self-care.

Implementing trauma-informed care is not without its challenges. The service delivery context, organizational values, and characteristics of providers and clients can affect training effectiveness and service delivery. In many health and human service organizations, delivery of quality services is often hampered by high staff turnover, resistance to change, limited resources, inadequate training opportuni- 
ties, limited career ladders, and uninformed provider work attitudes (Atkins et al., 1998; Glisson et al., 2008a, 2008b; Lorenzi \& Riley, 2000; McKay et al., 2006; Sexton \& Kelley, 2010). Limited time for staff to attend trainings and limited supervisory and clinical capacity can present real barriers to delivering trauma-informed care. Additionally, many providers in community agencies view the initiation of trauma-informed care as akin to opening Pandora's Box. They fear creating needs that cannot be met (Moses et al., 2003), and many express fear of having to deal with difficult topics like sexual abuse. Resistance to creating trauma-informed services, however, often stems from a lack of knowledge about the impact of trauma, uncertainty of appropriate service responses, and for some providers, unresolved personal traumas.

Despite these challenges, trauma-informed care represents a relatively lowcost and high-yield investment to address the high rates of trauma for children, youth, and families. The primary investment in staff training and workforce development ensures all those working with children and families have knowledge of trauma. Systems change demands commitments by leadership to set clear expectations of how organizations will and will not operate and to ensure staff have the resources they need to do the job. Current research suggests that the potential benefits to children, youth, and families far outweigh the cost of system change.

\section{Evaluation and Outcomes of Trauma-Informed Care}

\section{Evaluation and Measurement}

Currently, there is not one standard of measurement to assess to what degree an organization is trauma-informed and if an organization providing comprehensive trauma-informed care produces better outcomes for the children and families served. As an organizational framework, trauma-informed care encompasses everything from the physical environment to the quality of client interactions with staff. Without a standard of measurement, it is difficult to definitively link the degree of "trauma-informedness" of an organization (e.g., high or low trauma-informed) to indicators of well-being for children and families, (e.g. PTSD symptom reduction, a decrease in child welfare or justice involvement, and an increase in residential stability).

Over the years, research utilizing various organizational climate scales has been done to identify factors within the environment that affect staff attitudes and behaviors, as well as treatment outcomes (Friedman, Clickman, \& Kovach, 1986; Holahan \& Moos, 1982; Moos \& Moos, 1983; Lemke \& Moos, 1987). One of the most well-known social climate scales is the Community Oriented Programs Environment Scale (COPES) (Moos, 1974). Developed by Rudolph Moos to evaluate the social environment of residential treatment facilities for emotionally disturbed children, this standardized social climate scale assesses a program's internal functioning and allows for comparison across programs. The Survey of Organizational 
Functioning (SOF) measures organizational climate and culture, motivation for change, and staff attributes (Lehman, Greener, \& Simpson, 2002). The Center for Disease Control's (CDC's) questionnaire, the KABB, measures the effectiveness of a training program on intimate partner violence (IPV) by focusing on health professional staff's knowledge, attitude, beliefs, and behaviors (Gadomski et al., 2001; Soliman, 2001).

Although organizational climate scales can be used to assess an organization's culture, to date none of these have been adapted or tested to specifically measure the degree and effectiveness of trauma-informed care. Process tools that help organizations become trauma-informed provide benchmarks for organizational change, but these tools are not validated, standardized instruments with psychometric properties. A review of literature suggests that no standardized instruments of trauma-informed care currently exist.

\section{Outcomes}

In 2010, Hopper, Bassuk, and Olivet conducted a comprehensive review of the field to assess the level of trauma-informed care as an emerging, promising practice. Their review included a synthesis of published quantitative and qualitative studies, community-based program evaluations, and unpublished pilot studies. They also made contact with programs that were utilizing trauma-informed care models, and gaps in the field were identified. A variety of promising outcomes were found.

The most studied model to date is Sanctuary (Bloom, 1997). A series of studies have been conducted to assess the extent to which programs using Sanctuary were operating as therapeutic communities, as compared to traditional residential treatment units (Rivard et al., 2003; Rivard et al., 2004; Rivard, Bloom, McCorckle, \& Abramovits, 2005). Assessed using various combinations of organizational scales, such as COPES, youth measures (for example, Rosenberg Self-esteem Scale and the Child Behavior Checklist), and focus groups, positive changes in residential treatment environments serving youth have been noted (e.g., greater empathy by staff and greater sense of safety in environment). Focus groups indicated a growing awareness and understanding among staff of trauma and its impact, however only minor effects were noted on individual client behaviors.

Overall, preliminary outcomes associated with trauma-informed care include decreased emotional reactions for program participants, decreased crises in programs, enhanced sense of safety, and greater collaboration among service providers (Community Connections, 2002; Cocozza et al., 2005; Morrissey, Ellis, \& Gatz, 2005; Noether et al., 2007). A few pilot programs have demonstrated some improvement in client functioning in trauma-informed service settings (Morrissey, Jackson, \& Ellis, 2005; Kramer, unpublished), suggesting that trauma-informed care is a cost-effective approach to addressing trauma as compared to standard or traditional programming (Domino, Morrissey, Chung, Hunington, Larson, \& Russell, 2005). 


\section{Implications and Next Steps for the Field}

The study of traumatic stress evolved alongside significant cultural and political shifts that brought trauma into society's consciousness. This context supported the rights of the victimized, prioritized the need for healing relationships and recovery-oriented environments, and politically gave "voice to the disempowered" (Herman, 1992, p. 9). The concept of trauma-informed care emerged from this ever-evolving recognition and understanding of trauma and the role of the broader environment in addressing this public health issue.

Despite the recent calls for trauma-informed care across service sectors, the current discourse indicates a lack of clarity. Providers, policymakers, funders, and researchers vary widely in their understandings of the concept and use of the term, and may disagree about the relative efficacy of trauma-specific services versus trauma-informed care. Trauma-specific services refers to clinical interventions that treat symptoms of PTSD. Trauma-informed care refers to practices and policies that can be implemented by entire organizations, not just clinical staff, and involves modifications to organizational culture and practice (Guarino et al., 2009; Harris \& Fallot, 2001; SAMHSA, 2014). Despite the distinction, sometimes the terms are used interchangeably, which confounds the evidence base.

Currently, the field has an array of process tools that assist organizations in becoming trauma-informed, but data are lacking about the effectiveness of trauma-informed environments (Hopper et al., 2010). To move forward, the evolution of trauma-informed care will require (a) a clear consensus on the definition, principles, and components of trauma-informed care to create a uniform set of practice guidelines; (b) instrumentation to measure its effectiveness and assess organizations to capture their degree of trauma-informed care and its link to client-level indices of well-being; (c) methodologically rigorous studies to build the evidence base of trauma-informed care as a framework and complement to trauma-specific services, and; (d) public and private support, at the federal, state and local levels, to fund research and implementation.

Taking these next steps will require a shift in priorities and a commitment by leaders at all levels to invest in developing the human service workforce. In this time of shifting paradigms, we have a choice. If we simply react to its current popularity only to lapse back into more comfortable and familiar patterns, we run the risk of trauma-informed care being nothing more than a passing fad. However, if we respond by acknowledging the extent of trauma in the lives of children and families, we can transform our systems to be more responsive to all. Compared to the human and economic toll of unaddressed trauma, trauma-informed care implemented across service systems represents a relatively low-cost approach to address human suffering. 


\section{Conclusion}

Given the widespread prevalence of violence and trauma in the lives of children and families, there is a consensus that all service systems become "traumainformed" (Report of the Federal Partners Committee on Women and Trauma, 2011; SAMHSA, 2014). However, there remains a lack of clarity about the concept and inconsistency in its implementation (Hopper et al., 2010). Shifting from the dominant paradigm is no small feat. Professionals are often reluctant to let go of accepted models or theories that are familiar, and systems are strongly resistant to change (Lorenzi \& Riley, 2000). Are we ready to shift our public service systems and respond to trauma in coordinated, evidence-based ways? Are we ready to invest in the human service workforce, many of whom are paraprofessionals, to make trauma-informed care a standard of care? If we don't make this investment, it is likely that the current wave of interest will crest and eventually succumb to the forces of history as we once again deny the extent of trauma in the lives of children and families. When we look into the eyes of a child who has experienced trauma, the real question we must ask ourselves is: how can we not?

\section{References}

American Psychiatric Association. (2013). Diagnostic and statistical manual of mental disorders (5th ed.). Arlington, VA: American Psychiatric Publishing.

American Psychological Association. (2008). APA presidential task force on posttraumatic stress disorder and trauma in children and adolescents. Washington, DC: Author.

Anooshian, L. J. (2005). Violence and aggression in the lives of homeless children. Journal of Family Violence, 20, 373-387.

Atkins, M. S., McKay, M. M., Arvanitis, P., London, L., Madison, S., Costigan, C., ... Webster, D. (1998). An ecological model for school-based mental health services for urban low-income aggressive children. The Journal of Behavioral Health Services Research, 5(1), 64-75.

Bassuk, E., Weinreb, L., Buckner, J., Browne, A., Soloman, A., \& Bassuk, S. (1996). The characteristics and needs of sheltered homeless and low-income housed mothers. Journal of the American Medical Association, 276, 640-646.

Bassuk, E., Buckner, J., Weinreb, L., Browne, A., Bassuk, S., Dawson, R., \& Perloff, J. (1997). Homelessness in female-headed families: Childhood and adult risk and protective factors. American Journal of Public Health, 87, 241-248. 
Battle C., Zlotnick C., Najavits, L. M., Gutierrez, M., \& Winsor, C. (2002). Posttraumatic stress disorder and substance use disorder among incarcerated women. In P. Ouimette \& P. J. Brown (Eds.), Trauma and substance abuse: Causes, consequences, and treatment of comorbid disorders (pp. 209-226). Washington, DC: American Psychological Association.

Berliner, D. C. (2006). Our impoverished view of educational reform. Teachers College Record, 108(6), 949-995.

Benedek, D. M., \& Ursano, R. J. (2009). Posttraumtic stress disorder: From phenomenology to clinical practice. FOCUS: The Journal of Lifelong Learning in Psychiatry, 7, 160-175.

Bloom, S. (1997). Creating sanctuary: Toward the evolution of sane societies. New York, NY: Routledge.

Bloom, S. L. (2000). Origins of international society for traumatic stress studies. In A. Shalev, R. Yehuda, \& A. McFarlane (Eds.), International handbook of human response to trauma (27-50). New York, NY: Plenum Publishing.

Bonanno, G. A., Keltner, D., Holen, A., \& Horowitz, M. J. (1995). When avoiding unpleasant emotions might not be such a bad thing: Verbal-autonomic response dissociation and midlife conjugal bereavement. Journal of Personality and Social Psychology, 69(5), 975-989.

Bonanno, G. A., Keltner, D., Knoll, J. G., \& Putnam, F. (2002). When the face reveals what words do not: Facial expressions of emotion, smiling, and the willingness to disclose childhood sexual abuse. Journal of Personality and Social Psychology, 83(1), 94-110.

Bonanno, G. A. (2004). Loss, trauma, and human resilience: Have we underestimated the human capacity to thrive after extremely aversive events? American Psychologist, 59, 20-28.

Bonanno, G. A. (2014). Trauma and resilience: From heterogeneity to flexibility. Webinar sponsored by the International Society for the Study of Traumatic Stress, 7/10/14.

Bronfenbrenner, U., \& Morris, P. (1998). The ecology of developmental processes. In W. Damon (Ed.), Handbook of child psychology, 1: Theoretical models of human development (5th ed.) (pp. 993-1023). New York, NY: John Wiley \& Sons. 
Catlett, B. S., Toews, M. L., \& Walilko, V. (2010). Men's gendered constructions of intimate partner violence as predictors of court-mandated batterer treatment drop out. American Journal of Community Psychology, 45(1-2), 107-123.

Centers for Disease Control and Prevention. (2010). National intimate partner and sexual violence survey: 2010 summary report. Retrieved from http:// www.cdc.gov/violenceprevention/pdf/nisvs_report2010-a.pdf

Centers for Disease Control and Prevention. (2012a). Sexual violence: Facts at a glance. Retrieved from http://www.cdc.gov/ViolencePrevention/pdf/svdatasheet-a.pdf

Center for Disease Control. (2012b). Child abuse and neglect cost the United States $\$ 124$ billion. Rivals cost of other high profile public health problems [Press Release]. Retrieved from http://www.cdc.gov/media/releases/2012/ p0201_child_abuse.html

Center on the Developing Child at Harvard University. (2010). The foundations of lifelong health are built in early childhood. Retrieved from http://www. developingchild.harvard.edu

Chadwick Center for Children \& Families. (2013). Trauma System Readiness Tool. Retrieved from http://surveygizmolibrary.s3.amazonaws.com/library/113599/TraumaSystemReadinessTool2.pdf

Clervil, R., \& DeCandia, C. J. (2013). Integrating and sustaining trauma-informed care across diverse service systems. Waltham, MA: The National Center on Family Homelessness at American Institutes for Research.

Clervil, R., Guarino, K., DeCandia, C. J., \& Beach, C. A. (2013). Trauma-informed care for displaced populations: A guide for community-based service providers. Needham, MA: The National Center on Family Homelessness.

Cocozza, J. J., Jackson, E. W., Hennigan, K., Morrissey, J. B., Reed, B. G., \& Fallot, R. (2005). Outcomes for women with co-occurring disorders and trauma: Program-level effects. Journal of Substance Abuse Treatment, 28(2), 109-119.

Cohen, J., Perel, J., DeBellis, M., Friedman, M., \& Putnam, F. (2002). Treating traumatized children: Clinical implications of the psychobiology of posttraumatic stress disorder. Trauma, Violence \& Abuse, 3(2), 91-108. 
Community Connections. (2002). Trauma and abuse in the lives of homeless men and women. Online PowerPoint presentation. Washington, D.C. Retrieved from http:/www.pathprogram.samhsa.gov/ppt/Traumaand Homelessness. ppt

Copeland, W. E., Keeler, G., Angold, A., \& Costello, E. (2007). Traumatic events and posttraumatic stress in children. Archives of General Psychiatry, 64(5), $577-584$.

Cook, A., Spinazzola, J., Ford, J., Lanktree, C., Blaustein, M. Cloitre, M., \& van der Kolk, B. (2005). Complex trauma in children and adolescents. Psychiatric Annals, 35(5), 390-398.

Cusack, K. J., Frueh, C. B., Hiers, T., Suffoletta-Maierle, S., \& Bennett, S. (2003). Trauma within the psychiatric setting: A preliminary empirical report. Administration and Policy in Mental Health and Mental Health Services Research, 30, 453-460.

Cutuli, J. J., \& Herbers, J. E. (2014). Promoting resilience for children who experience family homelessness: Opportunities to encourage developmental competence. Cityscape: A Journal of Policy Development and Research, 16, 113-139.

Daly, J. E., Power, T. G., \& Gondolf, E. W. (2001). Predictors of batterer program attendance. Journal of Interpersonal Violence, 16(10), 971-991.

D'Andrea, W., Ford, J., Stolbach, B., Spinazzola, J., \& van der Kolk, B. (2012). Understanding interpersonal trauma in children: Why we need a developmentally appropriate trauma diagnosis. American Journal of Orthopsychiatry, 82(2), 187-200.

Domino, M. E., Morrissey, J. P., Chung, S., Huntington, N., Larson, M. J., \& Russell, L. A. (2005). Service use and costs for women with co-occurring mental and substance use disorders and a history of violence. Psychiatric Services, 56, 1223-1232.

Ehrensaft, M. K., Cohen, P., Brown, J., Smailes, E., Chen, H., \& Johnson, J. G. (2003). Intergenerational transmission of partner violence: A 20-year prospective study. Journal of Consulting and Clinical Psychology, 71(4), 741.

Elliott, D. E., Bjelajac, P., Fallot, R. D., Markoff, L. S., \& Reed, B. G. (2005). Traumainformed or trauma-denied: Principles and implementation of trauma-informed services for women. Journal of Community Psychology, 33(4), 461-477. 
Fairbank, J. A., \& Fairbank, D. W. (2009). Epidemiology of child traumatic stress. Current Psychiatry Reports, 11(4), 289-295.

Fallot, R., \& Harris, M. (2011). Creating cultures of trauma-informed care (CCTIC): A self-assessment and planning protocol. Community Connections. Retrieved from http://communityconnectionsdc.org/web/page/673/ interior.html

Fang, X., Brown, D., Florence, C., \& Mercy, J. (2012). The economic burden of child maltreatment in the United States and implications for prevention. Child Abuse \& Neglect, 36, 156-165.

Felitti, V. J., Anda, R. F., Nordenberg, D., Williamson, D. F., Spitz, A. M., Edwards, V., ... Marks, J. S. (1998). The relationship of adult health status to childhood abuse and household dysfunction. American Journal of Preventive Medicine, 14(4), 245-258.

Felitti, V. J., \& Anda, R. F. (2010). The relationship of adverse childhood experiences to adult health, well-being, social function, and health care. In R. Lanius, E. Vermetten, \& C. Pain (Eds.), The effects of early life trauma on health and disease: The hidden epidemic. New York, NY: Cambridge University Press.

Figley, C. R. (2002). Origins of traumatology and prospects for the future. Journal of Trauma Practice, 1, 17-32.

Finkelhor, D., Turner, H. A., Ormrod, R., Hamby, S. L., \& Kracke, K. (2009). Children's exposure to violence: A comprehensive national survey. Bulletin. Washington, DC: U.S. Department of Justice, Office of Justice Programs, Office of Juvenile Justice and Delinquency Prevention.

Ford, J. D., Hartman, J. K., Hawke, J., \& Chapman, J. F. (2008). Traumatic victimization, posttraumatic stress disorder, suicidal ideation, and substance abuse risk among juvenile justice-involved youths. Journal of Childhood and Adolescent Trauma, 1, 75-92.

Friedman, A., Glickman, N., \& Kovach, J. (1986). Comparisons of perceptions of the environments of adolescent drug treatment and residential outpatient programs by staff versus client and sex of staff and client. American Journal of Drug and Alcohol Abuse, 12(1-2), 31-52. 
Friedman, S. H., \& Loue, S. (2007). Incidence and prevalence of intimate partner violence by and against women with severe mental illness. Journal of Women's Health (Larchmt), 16(4), 471-480.

Gadomski, A. M., Wolff, D., Tripp, M., Lewis, C., \& Short, L. M. (2001). Changes in health care providers' knowledge, attitudes, beliefs, and behaviors regarding domestic violence, following a multifaceted intervention. Academic Medicine, 76, 1045-52.

Gewirtz, A. H. (2010). (Moving from evidence to action: The safe start series on children exposed to violence, Issue Brief \#6). Homeless shelters, permanent/ supportive housing, and transitional housing. North Bethesda, MD: Safe Start Center, Office of Juvenile Justice and Delinquency Prevention, Office of Justice Programs, U.S. Department of Justice.

Glisson, C., Schoenwald, S. K., Kelleher, K., Landsverk, J., Hoagwood, K. E., Mayberg, S., Green, P., \& Research Network on Youth Mental Health. (2008a). Therapist turnover and new program sustainability in mental health clinics as a function of organizational culture, climate, and service structure. Administration and Policy in Mental Health, 35(1-2), 124-33.

Glisson, C., Landsverk, J., Schoenwald, S., Kelleher, K., Hoagwood, K. E., Mayberg, S., Green, P., \& Research Network on Youth Mental Health. (2008b). Assessing the organizational social context (OSC) of mental health services: implications for research and practice. Administration and Policy in Mental Health, 35(1-2), 98-113.

Goodman, L. A., Thompson, K. M., Weinfurt, K., Corl, S., Acker, P., Mueser, K. T., \& Rosenberg, S. D. (1999). Reliability of reports of violent victimization and posttraumatic stress disorder among men and women with serious mental illness. Journal of Traumatic Stress, 12, 587-599.

Goodwin, S. N., Chandler, D., \& Meisel, J. (2003). Violence against women: The role of welfare reform. Washington, DC: National Institute of Justice.

Guarino, K., Soares, P., Konnath, K., Clervil, R., \& Bassuk, E. (2009). Traumainformed organizational toolkit. Rockville, MD: Center for Mental Health Services, Substance Abuse and Mental Health Services Administration, Daniels Fund, National Child Traumatic Stress Network, and W.K. Kellogg Foundation. Retrieved from http://homeless.samhsa.gov and http://www. familyhomelessness.org 
Guarino, K., \& Bassuk, E. (2010). Working with families experiencing homelessness: Understanding trauma and its impact. Zero to Three, 30(3), 11-20.

Guarino, K. (2011). Trauma-informed care for women veterans experiencing homelessness: A guide for service providers. Washington, DC: U.S. Department of Labor Women's Bureau.

Guarino, K. (2012). Developing a trauma-informed approach to serving young homeless families. Needham, MA: The National Center on Family Homelessness.

Guarino, K. (2014). Trauma-informed care for families experiencing homelessness. In M. Haskett, S. Perlman, \& B. Cowan (Eds.), Supporting families experiencing homelessness: Current practices and future directions (121-144). New York, NY: Springer.

Harris, M., \& Fallot, R. D. (Eds.). (2001). New directions for mental health services: Using trauma theory to design service systems. San Francisco, CA: Jossey-Bass.

Harvey, M. (2007). Towards an ecological understanding of resilience in trauma survivors: Implications for theory, research, and practice. Journal of Aggression, Maltreatment \& Trauma, 14, Issue 1-2, 9-32.

Hayes, M. A., Zonneville, M., \& Bassuk, E. (2013). The SHIFT study: Final report. Needham, MA: The National Center on Family Homelessness.

Heise, L., \& Garcia-Moreno, C. (2002). Violence by intimate partners. In E. G. Krug, L. L. Dahlberg, J. A. Mercy, A. B. Zwi, \& R. Lozano (Eds.), World report on violence and health (pp. 87-121). Geneva, Switzerland: World Health Organization.

Herman, J. (1992). Trauma and recovery. New York, NY: Basic Books.

Hodas, G. R. (2006). Responding to childhood trauma: The promise and practice of trauma informed care. Pennsylvania Office of Mental Health and Substance Abuse Services. Retrieved from http://www.nasmhpd.org/docs/ publications/docs/2006/Responding\%20to\%20Childhood\%20Trauma $\% 20$ $-\% 20$ Hodas.pdf

Holahan, C., \& Moos, R. (1982). Social support and adjustment: Predictive benefits of social climate indices. American Journal of Community Psychology, 10(4), 403-415. 
Hopper, E. K., Bassuk, E. L., \& Olivet, J. (2010). Shelter from the storm: Traumainformed care in homeless service settings. The Open Health Services and Policy Journal, 3, 80-100.

Hopson, L. M., \& Lee, E. (2011). Mitigating the effect of family poverty on academic and behavioral outcomes: The role of school climate in middle and high school. Children and Youth Services Review. 33(11), 2221-2229.

Jennings, A. (2004). The damaging consequences of violence and trauma: Facts, discussion points, and recommendations for the behavioral health system. Alexandria, VA: National Association of State Mental Health Program Directors, National Technical Assistance Center for State Mental Health Planning.

Jennings, A. (2008). Models for developing trauma-informed behavioral health systems and trauma-specific services. Alexandria, VA: National Association of State Mental Health Program Directors, National Technical Assistance Center for State Mental Health Planning. Retrieved from http://www.annafoundation.org/MDT.pdf

Kantor, G. K., \& Jasinski, J. L. (1998). Dynamics and risk factors in partner violence. Sage Publications, Inc.

Kessler, R. C. (2000). Posttraumatic stress disorder: The burden to the individual and to society. Journal of Clinical Psychiatry, 61, 4-12.

Kitzmann, K. M., Gaylord, N. K., Holt, A. R., \& Kenny, E. D. (2003). Child witnesses to domestic violence: A meta-analytic review. Journal of Consulting and Clinical Psychology, 71, 339-352.

Kramer, T. L., \& Greene, B. L. (1997). Post-traumatic stress disorder: A historical context and evolution. In D. E. Halpern (Ed.), States of mind: American and post-soviet perspectives on contemporary issues in psychology, 215-237. New York, NY: Oxford University Press.

Kramer, N. (n.d.). Project RISE evaluation report. Unpublished program evaluation report. Boston, MA: Health and Addictions Research, Inc. and Health Institute for Recovery.

Lehman, W. E. K., Greener, J. M., \& Simpson, D. D. (2002). Assessing organizational readiness for change. Journal of Substance Abuse Treatment, 22(4), 197-209. 
Lemke, S., \& Moos, R. (1987). Measuring the social climate of congregate residences for older people: Sheltered care environment scale. Psychology $\mathcal{E}$ Aging 2(1), 20-29.

Lipschitz, D. S., Winegar, R. K., Hartnick, E. M., Foote, B., \& Southwick, S. (1999). Posttraumatic stress disorder in hospitalized adolescents: Psychiatric comorbidity and clinical correlates. Journal of the American Academy of Child and Adolescent Psychiatry, 38, 385-392.

Lorenzi, N. M., \& Riley, R. T. (2000). Managing change: An overview. Journal of the American Medical Informatics Association, 7(Number 2, March), 116-124.

Macy, R. D., Behar, L. B., Paulson, R., Delman, J., \& Schmid, L. (2004). Community based acute post-traumatic stress management: A description and evaluation of a psychosocial intervention continuum. Harvard Review of Psychiatry, 12(4), 217-228.

Masten, A. S., \& Coatsworth, D. (1995). Competence, resilience, and psychopathology. In D. Cicchetti \& D. J. Cohen (Eds.), Developmental psychopathology Vol. 2: Risk, disorder, and adaptation (pp. 715-752). New York, NY: John Wiley.

Masten, A. S., \& Coatsworth, J. D. (1998). The development of competence in favorable and unfavorable environments: Lessons from successful children. American Psychologist, 53, 205-220.

Masten, A. S., Hubbard, J. J., Gest, S. D., Tellegen, A., Garmezy, N., \& Ramirez, M. L. (1999). Competence in the context of adversity: Pathways to resilience and maladaptation from childhood to late adolescence. Development and Psychopathology, 11, 143-169.

Masten, A. S., Herbers, J. E., Cutuli, J. J., \& Lafavor, T. L. (2008). Promoting competence and resilience in the school context. Professional School Counseling, $12,76-84$.

Masten, A. S. (2011). Resilience in children threatened by extreme adversity: Frameworks for research, practice, and translational synergy. Development and Psychopathology, 23, 493-506. 
McKay, M. M., Hibbert, R., Lawrence, R., Miranda, A., Paikoff, R., Bell, C., ... Bannon, W. (2006). Creating mechanisms for meaningful collaboration between members of urban communities and university-based HIV prevention researchers. Social Work in Mental Health, 5(1/2), 143-164.

McFarlane, A. C. (2000). On the social denial of trauma. In A. Shalev, R. Yehuda, \& A. McFarlane (Eds.), Handbook of human response to trauma (pp. 11-26). New York, NY: Plenum Publishing.

Moos, R. (1974). Evaluating treatment environments. New York, NY: John Wiley \& Sons.

Moos, R., \& Moos B. (1983). Adaptation and the quality of life in work and family settings. Journal of Community Psychology, 11, 158-170.

Morrissey, J. P., Ellis, A. R., \& Gatz, M. (2005). Outcomes for women with cooccurring disorders and trauma: Program and person-level effects. Journal of Substance Abuse Treatment, 28, 121-33.

Moses D. J., Reed B. G., Mazelis R., \& D’Ambrosio, B. (2003). Creating trauma services for women with co-occurring disorders: Experiences from the SAMHSA women with alcohol, drug abuse, and mental health disorders who have histories of violence study. Delmar, NY: Policy Research Associates. Retrieved from http://www.prainc.com/wcdvs/pdfs/LessonsFinal.pdf

Mowbray, C. T., Oyserman, D., Saunders, D., \& Rueda-Riedle, A. (1998). Women with severe mental disorders: Issues and service needs. In B. L. Levin, A. K. Blanch, \& A. Jennings, (Eds.), Women's mental health services: A public health perspective (pp. 175-200). Thousand Oaks, CA: Sage

Mueser, K. T., Goodman, L. B., Trumbetta, S. L., Rosenberg, S. D., Osher, F. C., Vidaver, R., \& Foy, D. W. (1998). Trauma and posttraumatic stress disorder in severe mental illness. Journal of Consult and Clinical Psychology, 66, 493-499.

National Center for Children in Poverty. (2007). Facts about trauma for policymakers: Children's mental health. New York, NY.

National Center for Injury Prevention and Control. (2003). Costs of intimate partner violence against women in the United States. Atlanta, GA: Centers for Disease Control and Prevention. 
National Center for Injury Prevention and Control. (2007). The cost of violence in the United States. Atlanta, GA: Centers for Disease Control and Prevention.

Unpublished, National Council for Behavioral Health. Organizational selfassessment: Adoption of trauma-informed care practice. Retrieved from http://www.thenationalcouncil.org/areas-of-expertise/trauma-informedbehavioral-healthcare/

National Scientific Council on the Developing Child. (2005). Excessive stress disrupts the architecture of the developing brain: Working paper no. 3. Retrieved from http://developingchild.harvard.edu

National Child Traumatic Stress Network Schools Committee. (2008). Child trauma toolkit for.educators. Los Angeles, CA, \& Durham, NC.

Noether, C. D., Brown, V., Finkelstein, N., Russell, L. A., VanDeMark, N. R., Morris, L. S., \& Graeber, C. (2007). Promoting resiliency in children of mothers with co-occurring disorders and histories of trauma: Impact of a skills-based intervention program on child outcomes. Journal of Community Psychology, 35, 823-843.

Pat-Horenczyk, R., Rabinowitz, R. G., Rice, A., \& Tucker-Levin, A. (2009). The search for risk and protective factors in childhood PTSD. In D. Brom, R. PatHorenczyk, \& J. D. Ford (Eds.), Treating traumatized children: Risk, resilience and recovery (pp. 51-71). New York, NY: Routledge.

Perry, B., Pollard, R., Blakeley, T., Baker, W., \& Vigiliante, D. (1996). Childhood trauma, the neurobiology of adaptation and use-dependent development of the brain: How 'states' becomes 'traits.' Infant Mental Health Journal, 16(4), 271-291.

Perry, B. D., \& Pollard, R. (1998). Homeostasis, stress, trauma, and adaptation: A neurodevelopmental view of childhood trauma. Child and Adolescent Psychiatric Clinics of North America, 7(1), 33-51.

Perry, B. D. (2001). The neurodevelopmental impact of violence in childhood. In D. Schetky \& E. Benedek (Eds.), Textbook of child and adolescent forensic psychiatry (pp. 221-238). Washington, DC: American Psychiatric Press.

Power, A. K. (2011). Breaking the silence. National Council Magazine, Issue 2, 10-11. Retrieved from http://www.integration.samhsa.gov/clinicalpractice/ sbirt/NC_Mag_Trauma_Web-Email.pdf 
Prescott, L., Soares, P., Konnath, K., \& Bassuk, E. (2008). A long journey home: A guide for creating trauma-informed services for mothers and children experiencing homelessness. Rockville, MD: Center for Mental Health Services; Substance Abuse and Mental Health Services Administration; the Daniels Fund; National Child Traumatic Stress Network; and the W.K. Kellogg Foundation. Retrieved fromhttp://www.homeless.samhsa.gov

Renner, L. M., \& Slack, K. S. (2006). Intimate partner violence and child maltreatment: Understanding intra- and intergenerational connections. Child Abuse \& Neglect, 30(6), 599-617.

Report of the Federal Partners Committee on Women and Trauma: A federal intergovernmental partnership on mental health transformation. (2011). Women and trauma. Retrieved from http://www.vawnet.org/Assoc_Files_ VAWnet/WomenAndTrauma.pdf

Rich, J. A., \& Grey, C. M. (2005). Pathways to recurrent trauma among young black men: Traumatic stress, substance use, and the "code of the street." American Journal of Public Health, 95(5), 816.

Ringel, S. (2012). Chapter 1 Overview. In S. Ringel \& J. R. Brandell (Eds.), Trauma: Contemporary directions in theory, practice, and research. Thousand Oaks, CA: SAGE.Publications, 1-12.

Rivard, J. C., Bloom, S. L., Abramovitz, R., Pasquale, L. E., Duncan, M., McCorkle, D., \& Gelman, A. (2003). Assessing the implementation and effects of a trauma-focused intervention for youths in residential treatment. Psychiatric Quarterly, 74(2), 137-154.

Rivard, J. C., McCorkle, D., Duncan, M., Pasquale, L., Bloom, S., \& Abramovitz, R. (2004). Implementing a trauma recovery framework for youths in residential treatment. Child and Adolescent Social Work Journal, 21(5), 529-550.

Rivard, J. C., Bloom, S. L., McCorkle, D., \& Abramovitz, R. (2005), Preliminary results of a study examining the implementation and effects of a trauma recovery framework for youths in residential treatment. Therapeutic Community: The International Journal for Therapeutic and Supportive Organizations, 26(1): 83-96.

Sarchiapone, M., Carli, V., Cuomo, C., Marchetti, M., \& Roy, A. (2009). Association between childhood trauma and aggression in male prisoners. Psychiatry Research, 165, 187-92. 
Saxe, G. N., Ellis, B. H., \& Kaplow, J. B. (2006). Collaborative treatment of traumatized children and teens: The trauma systems therapy approach. New York, NY: Guilford.

Sexton, T. S., \& Kelley, S. D. (2010). Finding the common core: Evidence-based practices, clinically relevant evidence, and mechanisms of change. Administration and Policy in Mental Health and Mental Health Services Research. Special Issue: Psychotherapy Practice in Usual Care, 37(1-2), 81-88.

Shonkoff, J., \& Phillips, D. A. (Eds.). (2000). From neurons to neighborhoods: The science of early childhood development. Washington, DC: National Academy Press.

Shonkoff, J. P., Garner, A. S., The Committee on Psychosocial Aspects of Child and Family Health; Committee on Early Childhood, Adoption, and Dependent Care; \& Section on Developmental and Behavioral Pediatrics. (2012a). The lifelong effects of early childhood adversity and toxic stress. Pediatrics, 129, 232-246.

Shonkoff, J. P., Garner, A. S., The Committee on Psychosocial Aspects of Child and Family Health; Committee on Early Childhood, Adoption, and Dependent Care; \& Section on Developmental and Behavioral Pediatrics. (2012b). Early childhood adversity, toxic stress, and the role of the pediatrician: Translating developmental science into lifelong health. Pediatrics, 129, 224-231.

Soliman, H., Rasquinha, S., Burkett, A., \& Shelton, S. (2001). Counselors' satisfaction with disaster training. Journal of Social Service Research, 27, 61-78.

Stukes Chipungu, S., \& Bent-Goodley, T. B. (2004). Meeting the challenges of contemporary foster care. The Future of Children, 14, 75-93.

Substance Abuse and Mental Health Services Administration (SAMHSA). (2014). Trauma-informed care in behavioral health services: A treatment protocol (TIP), SERIES 57. HHS Publication No. (SMA) 14-4816. Rockville, MD.

Terr, L. (1990). Too scared to cry: Psychic trauma in childhood. New York, NY: Harper Row.

U.S. Department of Health and Human Services, Administration of Children and Families. (2012). Adoption and foster care analysis and reporting system (AFCARS), FY 2011. Washington, DC. 
United States Department of Veterans Affairs, National Center on PTSD. (2014). PTSD history and overview. Retrieved from http://www.ptsd.va.gov/professional/PTSD-overview/ptsd-overview.asp

van der Kolk, B. A., Roth, S., Pelcovitz, D., Sunday, S., \& Spinazzola, J. (2005).

Disorders of extreme stress: The empirical foundation of a complex adaptation to trauma. Journal of Traumatic Stress, 18, 389-399.

Wolfe, D. A., Crooks, C. V., Lee, V., McIntyre-Smith, A., \& Jaffe, P. G. (2003). The effects of children's exposure to domestic violence: A meta-analysis and critique. Clinical Child and Family Psychology Review, 6(3), 171-187.

Yoe, J., Hornby, H., Goan, S., \& Tiernan, C. (2012). System of Care Trauma-Informed Agency Assessment (TIAA). Retrieved from http://thriveinitiative. org/wp-content/uploads/2012/10/TIAA-General-User-Overview-Manual. pdf

Zlotnick, C., Najavits, L. M., Rohsenow, D. J., \& Johnson, D. M. (2003). A cognitive-behavioral treatment program for incarcerated women with substance abuse disorder and post-traumatic stress disorder: Findings from a pilot study. Journal of Substance Abuse Treatment, 25, 99-105. 